\title{
Investigating the association of health system characteristics and health care utilization: a multilevel model in China's ageing population
}

\author{
Chaofan $\mathrm{Li}^{1}$, Chengxiang Tang ${ }^{2}$, \\ Haipeng Wang ${ }^{3,4}$ \\ ${ }^{1}$ Tsinghua Shenzhen International Graduate \\ School, Tsinghua University, Shenzhen, \\ Guangdong, China \\ ${ }^{2}$ School of Public Administration, Guangzhou \\ University, Guangzhou, Guangdong, China \\ ${ }^{3}$ Centre for Health Management and Policy \\ Research, School of Public Health, Cheeloo \\ College of Medicine, Shandong University, \\ Jinan, Shandong, China \\ ${ }^{4} \mathrm{NHC}$ Key Laboratory of Health Economics and \\ Policy Research (Shandong University), Jinan, \\ Shandong, China
}

\section{Correspondence to:}

Haipeng Wang

Centre for Health Management and Policy Research

School of Public Health

Cheeloo College of Medicine

Shandong University

Wenhua Xi Rd 44

Lixia District, Ji'nan

Shandong

China

wanghaipeng@sdu.edu.cn.
Background To achieve universal health coverage in China, it is necessary to identify access barriers to health care. This study examined the association between health system characteristics and health care utilization in China and identified factors associated with accessing health care among the mid-aged and elderly.

Methods Data were obtained from the 2015 China Health and Retirement Longitudinal Study, and 17370 respondents aged 45 and above were included in the analysis. The dependent variables were the use of outpatient and inpatient care among respondents. Health system characteristics at the provincial level were measured using the density of doctors and ward beds, health expenditure per visit/admission and health financing. A two-level logistic regression model was constructed to examine association between health care utilization and health system characteristics, controlling for predisposing, enabling and need variables.

Results Of the 17370 respondents, $18.3 \%$ had utilized outpatient care and $13.7 \%$ had utilized inpatient care in 2015. Increases in the share of out-of-pocket (OOP) payments as total health spending at the provincial-level was less likely to be associated with outpatient care utilization (odds ratio $(O R)=0.96,95 \%$ confidence interval $(C I)=0.93-0.98)$ among the mid-age and elderly population. Increases in the share of OOP payments $(\mathrm{OR}=0.98,95 \% \mathrm{CI}=0.97$ $1.00)$ and health expenditure per admission $(\mathrm{OR}=0.20,95 \%$ $\mathrm{CI}=0.04-0.88$ ) were less likely to be associated with inpatient care utilization, while increases in the density of beds (OR $=1.26,95 \%$ $\mathrm{CI}=1.10-1.43$ ) was more likely to be associated with inpatient care utilization. gross domestic product (GDP) per capita at the provincial level and types of health insurance owned by respondents were significantly related to both inpatient and outpatient care utilization.

Conclusions Low affordability of the mid-aged and elderly population is the main barrier to utilizing health care in China. In order to improve access to health care, the government should make more efforts, such as improving health insurance reimbursement rates and implementing prospective provider payment methods, to decrease OOP payment for the ageing population. 
Achieving equal access to health care is an important health policy goal in most countries [1-3]. According to the Sustainable Development Goals set by the United Nations in 2015, every country should take action to achieve universal health coverage (UHC), including the provision of financial risk protection and access to health care for all [4]. In China, the 2009 health care reform had set the goal to improve equitable access to basic health services for all through establishing universal health insurance coverage and reforming health care delivery system [5].

China has three social health insurance programs, including the Urban Employees' Basic Medical Insurance (UEBMI, launched in 1997), the New Cooperative Medical Scheme (NCMS, launched in 2003), and the Urban Residents' Basic Medical Insurance (URBMI, launched in 2007), which were established to cover all China's citizens and to improve equal access to health care for all [5]. Since 2011, China almost achieved universal health insurance coverage [6]. However, variations exist across insurance programs in terms of their premiums, pooled level, benefit package and reimbursement rates, which creates barriers to equal access to health care [7].

Since the health care reform, China made a lot of efforts and investments to build medical infrastructure and strengthen the health workforce, and achieved great improvements in the availability of health care during the past decade. The ward beds per 1000 inhabitants has increased from 3.3 in 2009 to 5.1 in 2015, and density of health professionals increased from 4.2 to 5.8 [8].

Although China made a number of efforts to improve access to health care $[9,10]$, inequity in health care utilization still exists across different groups with different income and education levels, as well as across regions $[11,12]$. Due to fast aging of populations, access to care has become a major issue for mid-aged and elderly adults in China. The older adults usually have high prevalence of non-communicable diseases, and high levels of functional impairment $[13,14]$. The ageing population met huge and urgent health care demands, which posed great challenge on the health care system. Therefore, it is necessary to identify barriers to equal access to health care among mid-aged and elderly adults, which could provide policy implications to improve access to care for all and achieve UHC in China.

Access to health care is a complex concept. Although some researchers defined access as freedom or opportunity to use health services [15], most viewed access as timely actual use of health services according to need $[16,17]$. There is consensus that access should reflect the "degree of fit" between supply- and demand-related factors and address the barriers to access from both the demand and the supply side [18,19]. To identify barriers to access from two sides empirically, in this paper, we defined access as health services utilization [20-24]. Andersen developed a behavior model of health care utilization comprising contextual and individual characteristics to identify access barriers to health care from both supply and demand perspectives [25]. Andersen's behavior model can be used as conceptual framework to identify barriers and examine factors associated with access to health care. We attempted to apply them into a two-level analytical framework consisting of health system characteristics as high-level factors and individual characteristics as the first-level factors. The simplified analytical framework of health care utilization with health system and individual characteristics is provided in Figure S1 in the Online Supplementary Document.

Previous studies mainly focused on individual and household characteristics of health care utilization, highlighting the association of both individual and province-level factors with health inequity among older people in China [26]. Moreover, some studies explored regional variations in medical resource allocation and health care service provision [27]. These studies identified barriers in access to health services from individual factors. A review of China's studies on health care utilization studies found that empirical research in China paid greater attention to individual factors rather than contextual factors [28]. To our knowledge, only a few studies focused on the association between contextual factors and health care utilization in China. For example, Huang and Fan studied the correlation between contextual factors (e.g., region of residence and community characteristics) and preventative care utilization [29,30], and Jin found that higher density of health workforce was associated with improved health care accessibility [31]. However, little empirical research has examined the extent to which the health system characteristics are associated with health care utilization among the mid-aged and elderly in China. Therefore, a close examination of the association of health system characteristics and health care utilization in China is imperative.

This paper examined the association of health system characteristics and health care utilization among the mid-aged and elderly, and identified the main barriers in accessing health services from both the supply and demand sides. 


\section{METHODS}

\section{Selection and description of participants}

This study used a cross-sectional study design to examine the association between health system characteristics and health care utilization. Data were obtained from the fourth wave of the China Health and Retirement Longitudinal Study (CHARLS) that provided a nationally representative sample of mid-aged and elderly residents in China (http://charls.pku.edu.cn/index.html). Residents aged 45 and older were selected from 150 counties within 28 provinces (excluding Ningxia, Hainan, and Tibet) through multistage probability-proportional-to-size sampling methods. Participants were interviewed by a trained interviewer using face-to-face computer-assisted personal interviews and standardized questionnaires. More details on CHARLS can be found in the cohort profile, and data are publicly available at the website of the Institute of Social Science Survey, Peking University [32]. In 2015, 12221 households and 19840 family members aged 45 years or older were interviewed, with a response rate of $82.1 \%$. The inclusion criteria were: (1) aged 45 and above; (2) community-dwelling. Observations with missing values in key outcome and independent variables were excluded. The final sample size included in this study was 10923 households and 17370 respondents. Data on health system characteristics were obtained from the Statistical Yearbook of Health and Family Planning of China (2016), which included information on gross domestic product (GDP) per capita, health resource allocation, and health financing and expenditures at the provincial levels [8].

\section{Measurement}

Health care utilization refers to the use of services by persons to prevent and cure health problems, promote maintenance of health and well-being [33]. It could be broadly measured as, for example, whether or not a person was hospitalized or used outpatient care, emergency department and dental care or the frequency of these visits [34]. Van Doorslaer found that whether a person used health care rather than the number of visits that person occurred contribute to inequality in health care utilization [35]. Thus, we used dummy variables indicating whether or not the respondents used outpatient and inpatient care utilization, respectively, as the outcome variables in this study. Use of outpatient care was measured by asking respondents whether they visited the outpatient departments in a health institution or a physician office in the last month, while use of inpatient care was measured by asking respondents whether they received inpatient care in the past year. Both outcome variables were coded as dichotomous, with $0=$ no and $1=$ yes.

We measured the health system characteristics (including health financing and availability of health resources) using provincial-level data, because data at the county- and community-level are not available. Health care financing relates to people's affordability of health care. Consistent with previous studies, we measured health financing using three variables, including per capita GDP, per capita expenditure per visit or admission, and the share of out-of-pocket (OOP) payment of total health expenditure (THE) $[25,36,37]$. Per capita GDP varies across provinces in China. High health care expenditure per visit or admission and OOP payment share creates financial barriers to accessing health care.

The density of physicians and ward beds were used to measure the availability of health resources that determines the supply of health services. Based on previous studies and the statistical indicator used by the National Commission of Health in China, we used the number of health professionals and ward beds per 1000 residents to measure health resource availability $[17,38]$.

Individual-level characteristics included predisposing, health care needs, and enabling variables. Demographic characteristics, marital status, education, and occupation were selected as predisposing factors. Demographic characteristics included gender (female, male) and age groups (45-59, 60-74, 75 and above). Marital status was classified into two groups: (1) married and partnered, and (2) widowed, divorced, and others. Education was coded into four groups: (1) lower than primary school, (2) primary school, (3) middle school, and (4) high school and above. Occupation status was categorized into four groups: (1) agricultural work, (2) employed, (3) self-employed, and (4) unemployed and retired.

Enabling factors included types of health insurance coverage, areas of residence, and household income level. Health insurance coverage type was grouped into: (1) uninsured, (2) NCMS, (3) URBMI, (4) UEBMI, and (5) other health insurance schemes. Areas of residence were urban community and rural village areas. Household income level was grouped into quantiles based on the rank of per capita household consumption expenditure. Household consumption had proved to be a good measure for living standard in a prior study that also used CHARLS data [39]. 
Health care need variables included self-reported health status and diagnosis with chronic disease. Respondents were asked to rate their overall health status on a 5-point scale, including excellent, very good, good, fair, and poor, and was recoded into three categories: good, fair, and poor in the analysis. Fourteen categories of chronic disease were identified in the CHARLS survey, such as diabetes, hypertension, and chronic lung diseases. If a respondent reported that he or she had been diagnosed with any kind of chronic disease, he or she was considered being a person diagnosed with chronic disease, otherwise not.

\section{Statistical analysis}

We constructed a multi-level logistic regression model to examine the association of health care utilization between health system characteristics and individual characteristics. Following the procedure of developing a multilevel model suggested by Merlo and Sommet [40,41], we first ran a two-level logistic model with no individual- and provincial-level variables (null model):

$$
\begin{gathered}
\mathrm{Y}_{i j}=\beta_{0 j}+\varepsilon_{i j} \\
\beta_{0 j}=\gamma_{00}+\mu_{0 j}
\end{gathered}
$$

in which $Y_{i j}$ is the dummy outcome variable ( $i$ refers to the individual and $j$ refers to the province), $\beta_{0 j}$ is the mean of probability of health care utilization in province $j, \varepsilon_{\mathrm{ij}}$ is the residual component for individual $i$ in province $j, \gamma_{00}$ is the mean value of outcome variable across all provinces, and $\mu_{0 j}$ denotes the deviation of province j's mean from the grand mean of all individuals. $\mu_{0 j}$ usually refers to random intercept effect, which is assumed to have a mean of 0 and constant variance $\sigma^{2}$. Intraclass correlation (ICC) was calculated to assess the degree of variation that could be attributed to contextual level variables [42]:

$$
\text { ICC }=\frac{\delta_{b}^{2}}{\delta_{b}^{2}+\delta_{w}^{2}}
$$

in which $\sigma_{\mathrm{b}}{ }^{2}$ represents the between-province variance and $\sigma_{\mathrm{w}}{ }^{2}$ denotes the within-province variance. When the ICC is significantly different from zero, within-cluster correlation exists and one could consider running multilevel regression analysis [41]. Then, we included individual covariates to the first-level equation and fitted a random intercept model (Model 1):

$$
\begin{gathered}
Y_{i j}=\beta_{o j}+\beta_{i j} X_{i j}+\varepsilon_{i j} \\
\beta_{0 j}=\gamma_{00}+\mu_{0 j}
\end{gathered}
$$

in which $\mathrm{X}_{\mathrm{ij}}$ is the vector of individual predisposing, enabling, and need variables, and $\beta_{\mathrm{i}}$ denotes the vector of their coefficients. Lastly, we introduced the health system characteristics of each province into level-2 equations, controlling for individual factors to distinguish the association of health system characteristics and health care utilization (Model 2):

$$
\begin{aligned}
& Y_{i j}=\beta_{o j}+\beta_{i j} X_{i j}+\varepsilon_{i j} \\
& \beta_{0 j}=\gamma_{00}+\gamma_{k} z_{j}+\mu_{0 j}
\end{aligned}
$$

in which $Z_{j}$ is the vector of health system factors, and $\gamma_{k}$ denotes the vector of their coefficients. The odds ratio (OR) and 95\% confidence interval (CI) of covariates were estimated to represent the impact of individual characteristics and health system characteristics on health care utilization. Akaike information criterion, Bayesian information criterion and likelihood ratio test were used to compare the goodness of fit of different models [43]. All statistical analyses were conducted using the software Stata 15.0. (StataCorp LLC, College Station TX, USA).

\section{Ethics considerations}

This study is exempt because it used secondary data from the publicly available data source (http://charls. pku.edu.cn/index.html). The CHARLS was obtained ethical approval from the Ethical Review Committee at Peking University in January 2011.

\section{RESULTS}

\section{Health care utilization and basic characteristics of respondents}

Descriptive statistics of health care utilization and respondents' characteristics are presented in Table 1 . More than $18 \%$ of the mid-aged and elderly respondents had used outpatient care during the past month and about $14 \%$ had used hospitalization services during the last year. There were significant variations in 
Table 1. Descriptive characteristics of respondents

\begin{tabular}{|c|c|c|c|}
\hline Variabies & Categories & $\mathbb{N}$ & $\%$ \\
\hline \multirow{2}{*}{$\begin{array}{l}\text { Outpatient } \\
\text { care utilization }\end{array}$} & No & 14187 & 81.68 \\
\hline & Yes & 3183 & 18.32 \\
\hline \multirow{2}{*}{$\begin{array}{l}\text { Inpatient care } \\
\text { utilization }\end{array}$} & No & 14987 & 86.28 \\
\hline & Yes & 2383 & 13.72 \\
\hline \multirow{2}{*}{ Gender } & Female & 8854 & 50.97 \\
\hline & Male & 8516 & 49.03 \\
\hline \multirow{3}{*}{ Age } & $45-59$ & 8779 & 50.54 \\
\hline & $60-74$ & 7137 & 41.09 \\
\hline & $75+$ & 1454 & 8.37 \\
\hline \multirow{2}{*}{ Marital status } & Married and partnered & 15181 & 87.40 \\
\hline & Widowed, divorced and others & 2189 & 12.60 \\
\hline \multirow{4}{*}{ Education } & Lower than primary school & 7188 & 41.38 \\
\hline & Primary school & 4766 & 27.44 \\
\hline & Middle school & 3470 & 19.98 \\
\hline & High school and above & 1946 & 11.20 \\
\hline \multirow{4}{*}{$\begin{array}{l}\text { Occupation } \\
\text { status }\end{array}$} & Agricultural work & 7302 & 42.04 \\
\hline & Employed & 3192 & 18.38 \\
\hline & Self-employed & 1503 & 8.65 \\
\hline & Unemployed and retired & 5373 & 30.93 \\
\hline \multirow{3}{*}{$\begin{array}{l}\text { Self-reported } \\
\text { health status }\end{array}$} & Good & 4352 & 25.05 \\
\hline & Fair & 9131 & 52.57 \\
\hline & Poor & 3887 & 22.38 \\
\hline \multirow{2}{*}{$\begin{array}{l}\text { Chronic } \\
\text { disease }\end{array}$} & No & 5140 & 29.59 \\
\hline & Yes & 12230 & 70.41 \\
\hline \multirow{5}{*}{$\begin{array}{l}\text { Health } \\
\text { insurance } \\
\text { coverage }\end{array}$} & Uninsured & 1315 & 7.57 \\
\hline & NCMS & 11725 & 67.50 \\
\hline & URBMI & 1184 & 6.82 \\
\hline & UEBMI & 2024 & 11.65 \\
\hline & Others & 1122 & 6.46 \\
\hline \multirow{2}{*}{$\begin{array}{l}\text { Region of } \\
\text { residence }\end{array}$} & Urban community & 6733 & 38.76 \\
\hline & Rural village & 10637 & 61.24 \\
\hline Total & & 17370 & 100.00 \\
\hline
\end{tabular}

NCMS - New Cooperative Medical Schemes; URBMI - Urban Residents' Basic Medical Insurance; UEBMI - Urban Employees' Basic Medical Insurance. the use of outpatient and inpatient care utilization among mid-aged and elderly adults across provinces (Figure $\mathbf{1}$ ). The percent of outpatient visits during the last month ranged from 5\% to 38\% (Figure 1, Panel A), and the percent of inpatient visits during the last year varied from $4 \%$ to $27 \%$ (Figure 1, Panel B).

The majority ( $87 \%$ ) of residents were married or partnered, $41 \%$ were low-educated, $42 \%$ were engaged in agricultural work, 31\% were not working. More than half (53\%) reported fair health status and $70 \%$ were diagnosed with at least one kind of chronic disease. More than 22\% rated their health status as poor. Almost all respondents (92\%) had health insurance coverage, so only $8 \%$ were uninsured. More than $60 \%$ of respondents were living in rural villages, compared to $39 \%$ living in urban communities.

\section{Health system characteristic at the provincial level}

Figure 2 and Table S1 in the Online Supplementary Document show the economic development and several health system characteristics at the provincial level in China in 2015. Economic development varied greatly across provinces (Figure 2, Panel A), for example, per capita GDP in Beijing (CNY¥106497, US\$17099) was 3.13 times higher than that in Gansu (CNY¥26165, US\$4201). There were also large variations in health resources allocation across provinces. The number of ward beds per 1000 residents ranged from 4.02 to 6.37 (Figure 2, Panel B), while the number of health professionals per 1000 residents ranged from 4.6 to 10.4 (Figure 2, Panel C). Citizens in developed regions may also receive better financial protection for health services (Figure 2, Panel D). The share of OOP payment as THE in Beijing (17.39\%) was much lower than that in other provinces (around 30\%). Health expenditure per visit or admission also varied widely across provinces (Figure 2,
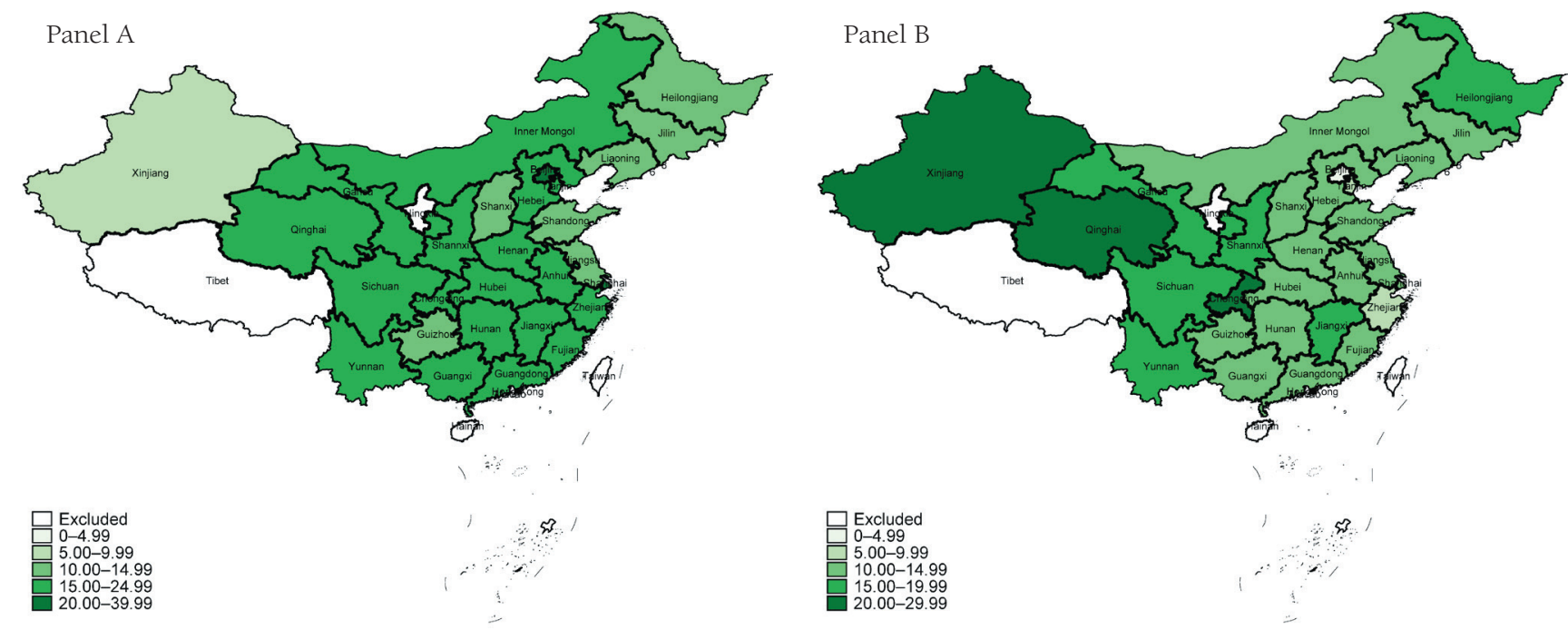

Figure 1. Probability of outpatient and inpatient care utilization among mid-aged and elderly in China in 2015. Panel A. Probability of outpatient care utilization. Panel B. Probability of inpatient care utilization. 

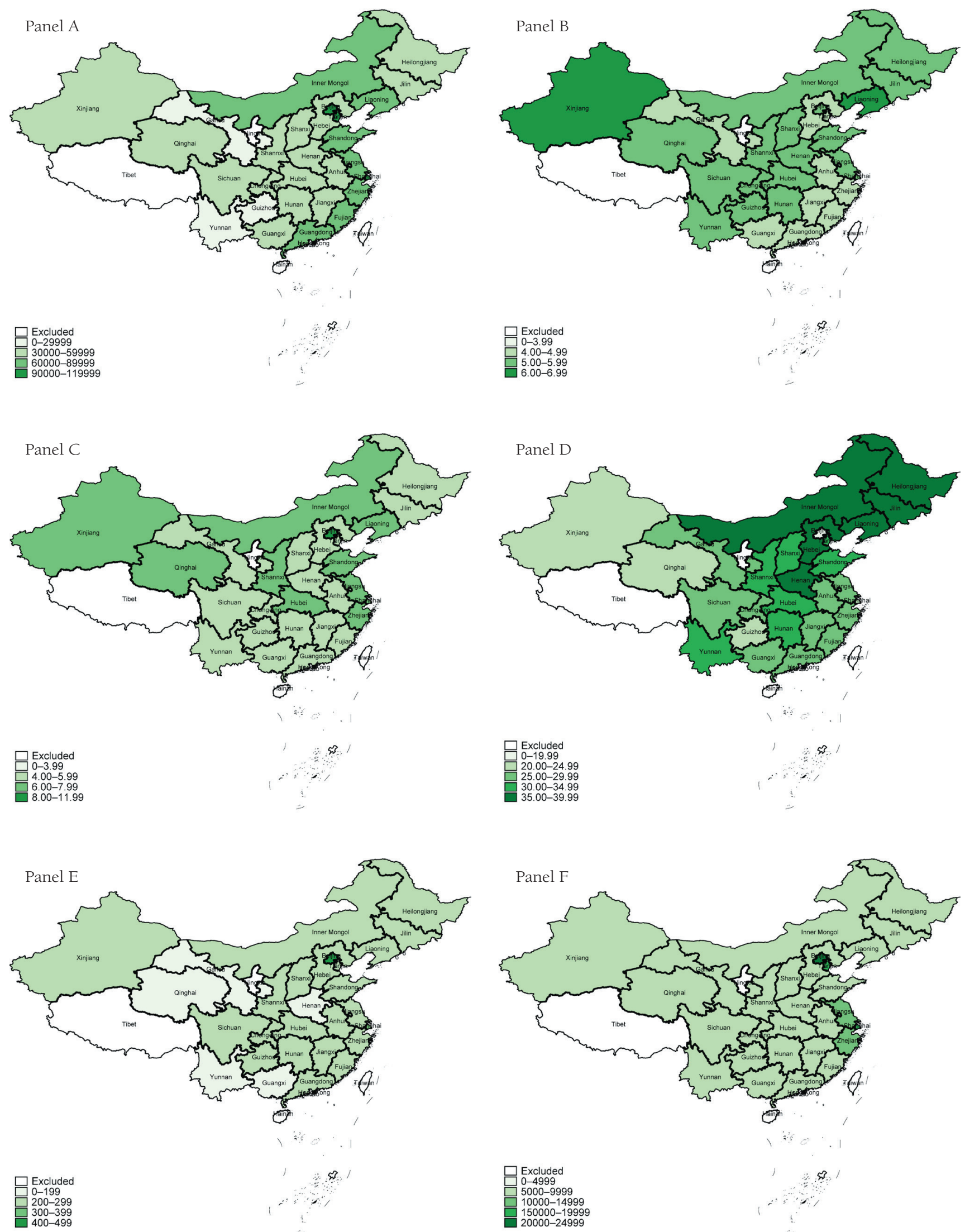

Figure 2. Economic development and health system characteristics of 28 provinces in China in 2015. Panel A. Gross Domestic Product Per capita (Chinese yuan). Panel B. Ward Beds per 1000 inhabitant. Panel C. Health professionals per 1000 inhabitants. Panel D. Share of out-of-pocket payment in total health expenditure (\%). Panel E. Outpatient expenditure per visits (Chinese yuan). Panel F. Inpatient expenditure per admission (Chinese yuan). 
Panels E and F), for example outpatient expenditure per visit in Beijing was 2.68 times as high as that in Henan province (CNY $¥ 40.90$ vs 164.40 , US\$70.79 vs 26.40), and inpatient expenditure per admission in Beijing was 3.74 times as high as that in Guizhou province (CNY¥20149.20 vs 5387.70, US\$ 3235.05 vs 865.02$)$.

\section{Health system characteristics and individual factors associated with health care utilization}

Table 2 reports the results from the multilevel logistic regression testing the association of outpatient care utilization with health system and individual characteristics. Compared to female respondents, male respondents were $0.80(95 \% \mathrm{CI}=0.73-0.87)$ times less likely to seek outpatient care. Respondents who

Table 2. Association of health system characteristics and outpatient care utilization: multilevel regression model

\begin{tabular}{|c|c|c|c|c|}
\hline \multirow{2}{*}{ VARIABIES } & \multirow{2}{*}{ Categoriles } & \multirow{2}{*}{$\begin{array}{c}\text { NULL MODEL } \\
\text { OR (95\% CI) }\end{array}$} & MODEL 1 & \multirow{2}{*}{$\begin{array}{c}\text { MODEL } 2 \\
\text { OR }(95 \% \text { CI })\end{array}$} \\
\hline & & & OR $(95 \% \mathrm{CI})$ & \\
\hline \multicolumn{5}{|l|}{ FIXED EFFECTS } \\
\hline \multicolumn{5}{|l|}{ Individual level: } \\
\hline \multicolumn{5}{|l|}{-Predisposing factors } \\
\hline Gender (ref=Female) & Male & & $0.80(0.73,0.87)$ 丰 & $0.80(0.73,0.87) \ddagger$ \\
\hline \multirow[t]{2}{*}{ Age $(r e f=45-59)$} & $60-74$ & & $1.01(0.92,1.11)$ & $1.01(0.92,1.11)$ \\
\hline & $75+$ & & $0.91(0.76,1.07)$ & $0.91(0.76,1.07)$ \\
\hline Marital status (ref= Married and partnered) & Widowed, divorced and others & & $1.02(0.90,1.15)$ & $1.02(0.90,1.15)$ \\
\hline \multirow[t]{3}{*}{ Education (ref=Lower than primary school) } & Primary school & & $1.07(0.97,1.19)$ & $1.07(0.97,1.19)$ \\
\hline & Middle school & & $1.09(0.97,1.23)$ & $1.09(0.97,1.23)$ \\
\hline & High school and above & & $1.24(1.06,1.45) \ddagger$ & $1.24(1.06,1.45)$ 丰 \\
\hline \multirow[t]{3}{*}{ Occupation status (ref = Agricultural work) } & Employed & & $0.88(0.77,1.00)^{*}$ & $0.88(0.77,1.00) \dagger$ \\
\hline & Self-employed & & $0.92(0.78,1.08)$ & $0.92(0.78,1.08)$ \\
\hline & Unemployed and retired & & $0.93(0.84,1.03)$ & $0.93(0.84,1.03)$ \\
\hline \multicolumn{5}{|l|}{ Need factors } \\
\hline \multirow[t]{2}{*}{ Self-reported health status (ref= Good) } & Fair & & $1.75(1.55,1.98) \ddagger$ & $1.76(1.56,1.98)$ 申 \\
\hline & Poor & & $3.30(2.89,3.77) \neq$ & $3.31(2.90,3.78)$ 丰 \\
\hline Chorionic disease $(\mathrm{ref}=\mathrm{No})$ & Yes & & $1.90(1.70,2.12) \neq$ & $1.90(1.70,2.12)$ † \\
\hline \multicolumn{5}{|l|}{ Enabling factors } \\
\hline \multirow[t]{4}{*}{ Health insurance $(\mathrm{ref}=$ Uninsured $)$} & NCMS & & $1.37(1.16,1.62) \neq$ & 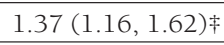 \\
\hline & URBMI & & $1.42(1.14,1.78) \ddagger$ & $1.42(1.14,1.78)$ † \\
\hline & UEBMI & & $1.57(1.28,1.94) \neq$ & 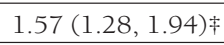 \\
\hline & Others & & $1.46(1.16,1.84) \neq$ & 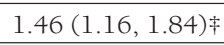 \\
\hline Region of residence (ref = urban community) & Rural village & & $1.13(1.03,1.25) \ddagger$ & 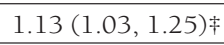 \\
\hline \multirow[t]{4}{*}{ Economic status (ref $=$ Poorest $)$} & 2 & & $1.11(0.97,1.26)$ & $1.11(0.97,1.26)$ \\
\hline & 3 & & $1.13(0.99,1.28)^{*}$ & $1.13(0.99,1.28) *$ \\
\hline & 4 & & $1.10(0.96,1.25)$ & $1.10(0.96,1.25)$ \\
\hline & Richest & & $1.26(1.101 .43) \ddagger$ & $1.25(1.09,1.42)$ 丰 \\
\hline Constant & & $0.22(0.19,0.25) \neq$ & $0.05(0.04,0.06) \neq$ & $0.01(0.00,0.96)$ \\
\hline \multicolumn{5}{|l|}{ Provincial level } \\
\hline \multicolumn{2}{|l|}{ Per capita GDP } & & & $1.57(1.03,2.40) \dagger$ \\
\hline \multicolumn{2}{|l|}{ Share of OOP in THE } & & & $0.96(0.93,0.98)$ ‡ \\
\hline \multicolumn{2}{|l|}{ Log of outpatient expenditure per visit } & & & $0.62(0.08,5.09)$ \\
\hline \multicolumn{2}{|c|}{ Number of health professionals per 1000 inhabitants } & & & $0.82(0.53,1.25)$ \\
\hline \multicolumn{5}{|l|}{ RANDOM EFFECTS } \\
\hline \multicolumn{2}{|l|}{ Level-2 intercept variance } & & $0.13(0.07,0.27)$ & $0.07(0.03,0.15)$ \\
\hline \multicolumn{2}{|l|}{ Number of observations } & 17370 & 17370 & 17370 \\
\hline \multicolumn{2}{|l|}{ AIC } & 16412.79 & 15637.34 & 15630.96 \\
\hline BIC & & 16428.31 & 15823.64 & 15848.31 \\
\hline Intraclass correlation & & 0.04 & 0.04 & 0.02 \\
\hline Log likelihood & & -8204.39 & -7794.67 & -7787.48 \\
\hline LR test statistic & & $P<0.001$ & $P<0.001$ & $P<0.001$ \\
\hline
\end{tabular}

OR - odds ratio; CI - confidence interval; NCMS - New Cooperative Medical Schemes; URBMI - Urban Residents' Basic Medical Insurance; UEBMI - Urban Employees' Basic Medical Insurance; GDP - Gross Domestic Product; OOP - out-of-pocket; THE - total health expenditure; AIC - Akaike information criterion; BIC - Bayesian information criterion; LR test - likelihood ratio test

$*, P<0.1 ; \dagger, P<0.05 ;$;,$P<0.01$ 
received high school and above education $(\mathrm{OR}=1.24,95 \% \mathrm{CI}=1.06-1.45)$ were more likely to seek outpatient care than those with low educational levels. The employed older adults had a lower likelihood of visiting physicians than respondents engaging in agricultural work $(\mathrm{OR}=0.88,95 \% \mathrm{CI}=0.77-1.00)$. After adjusting for predisposing factors, need factors were still associated with outpatient care utilization. Respondents who reported fair ( $\mathrm{OR}=1.76,95 \% \mathrm{CI}=1.56-1.98)$ and poor health status $(\mathrm{OR}=3.31,95 \%$ $\mathrm{CI}=2.90-3.78)$, and respondents diagnosed with chronic disease $(\mathrm{OR}=1.90,95 \% \mathrm{CI}=1.70-2.12)$ were more likely to use outpatient care than their counterparts. Moreover, health insurance coverage, residence in a rural village, and high economic status statistically were also positively associated with outpatient care utilization.

Table 3. Association of health system characteristics and inpatient care utilization: multilevel regression model

\begin{tabular}{|c|c|c|c|c|}
\hline \multirow{2}{*}{ Variables } & \multirow{2}{*}{ Categories } & NULL MODEL & MODEL 3 & Model 4 \\
\hline & & OR $(95 \% \mathrm{CI})$ & OR $(95 \% \mathrm{CI})$ & OR $(95 \% \mathrm{CI})$ \\
\hline \multicolumn{5}{|l|}{ FIXED EFFECTS } \\
\hline \multicolumn{5}{|l|}{ Individual level: } \\
\hline \multicolumn{5}{|l|}{ Predisposing factors } \\
\hline Gender (ref=Female) & Male & & $1.11(1.01,1.23) \dagger$ & $1.11(1.01,1.23) \dagger$ \\
\hline \multirow[t]{2}{*}{ Age $(r e f=45-59)$} & $60-74$ & & $1.24(1.11,1.38) \ddagger$ & $1.25(1.12,1.39) \ddagger$ \\
\hline & $75+$ & & $1.42(1.19,1.69) \ddagger$ & $1.43(1.20,1.70) \ddagger$ \\
\hline Marital status (ref= Married and partnered) & Widowed, divorced and others & & $1.03(0.90,1.18)$ & $1.03(0.90,1.17)$ \\
\hline \multirow[t]{3}{*}{ Education (ref=Lower than primary school) } & Primary school & & $0.96(0.85,1.08)$ & $0.96(0.85,1.08)$ \\
\hline & Middle school & & $0.94(0.82,1.08)$ & $0.94(0.82,1.08)$ \\
\hline & High school and above & & $0.78(0.65,0.94) \ddagger$ & $0.78(0.65,0.94) \ddagger$ \\
\hline \multirow[t]{3}{*}{ Occupation status (ref=Agricultural work) } & Employed & & $0.82(0.69,0.96) \dagger$ & $0.83(0.71,0.98) \dagger$ \\
\hline & Self-employed & & $1.18(0.98,1.43) *$ & $1.19(0.99,1.43) *$ \\
\hline & Unemployed and retired & & $1.59(1.41,1.79) \ddagger$ & $1.61(1.44,1.81) \ddagger$ \\
\hline \multicolumn{5}{|l|}{ Need factors: } \\
\hline \multirow[t]{2}{*}{ Self-reported health status (ref= Good) } & Fair & & $1.67(1.44,1.94) \ddagger$ & $1.67(1.44,1.93) \ddagger$ \\
\hline & Poor & & $4.16(3.57,4.86) \ddagger$ & $4.16(3.57,4.86) \ddagger$ \\
\hline Chorionic disease $(\mathrm{ref}=\mathrm{No})$ & Yes & & $2.32(2.01,2.67) \ddagger$ & $2.31(2.00,2.65) \ddagger$ \\
\hline \multicolumn{5}{|l|}{ Enabling factors } \\
\hline \multirow[t]{4}{*}{ Health insurance $(\mathrm{ref}=$ Uninsured $)$} & NCMS & & $1.43(1.18,1.74) \ddagger$ & $1.42(1.17,1.73) \dagger$ \\
\hline & URBMI & & $1.66(1.29,2.13) \ddagger$ & $1.64(1.28,2.10) \ddagger$ \\
\hline & UEBMI & & $1.69(1.34,2.13) \ddagger$ & $1.68(1.33,2.13) \ddagger$ \\
\hline & Others & & $1.58(1.22,2.05) \ddagger$ & $1.60(1.24,2.08) \ddagger$ \\
\hline Region of residence (ref = Urban community) & Rural village & & $1.02(0.91,1.14)$ & $1.00(0.89,1.11)$ \\
\hline \multirow[t]{4}{*}{ Economic status (ref= Poorest) } & 2 & & $1.18(1.00,1.38) \dagger$ & $1.18(1.00,1.38) \dagger$ \\
\hline & 3 & & $1.48(1.27,1.73) \ddagger$ & $1.48(1.27,1.73) \ddagger$ \\
\hline & 4 & & $1.76(1.51,2.05) \ddagger$ & $1.76(1.52,2.05) \ddagger$ \\
\hline & Richest & & $2.19(1.88,2.55) \ddagger$ & $2.19(1.88,2.56) \ddagger$ \\
\hline Constant & & $0.16(0.14,0.18)$ & $0.01(0.01,0.02) \ddagger$ & $5.68(0.21,151.84) \ddagger$ \\
\hline \multicolumn{5}{|l|}{ Provincial level: } \\
\hline Per capita GDP & & & & $0.99(0.69,1.42)$ \\
\hline Share of OOP in THE & & & & $0.98(0.97,1.00) \dagger$ \\
\hline Log of inpatient expenditure per admission & & & & $0.20(0.04,0.88) \dagger$ \\
\hline Ward Beds per 1000 inhabitants & & & & $1.21(1.09,1.35) \ddagger$ \\
\hline \multicolumn{5}{|l|}{ RANDOM EFFECTS } \\
\hline Level-2 intercept variance & & $0.05(0.02,0.12)$ & & $0.01(0.00,0.04)$ \\
\hline Number of observations & & 17370 & 17370 & 17370 \\
\hline AIC & & 13838.93 & 12483.55 & 12461.71 \\
\hline BIC & & 13854.45 & 12669.85 & 12679.06 \\
\hline Intraclass correlation & & 0.02 & 0.01 & 0.002 \\
\hline Log likelihood & & -6917.46 & -6217.77 & -6202.86 \\
\hline LR test statistic & & $P<0.001$ & $P<0.001$ & $P=0.07$ \\
\hline
\end{tabular}

OR - odds ratio, CI - confidence interval, NCMS - New Cooperative Medical Schemes, URBMI - Urban Residents' Basic Medical Insurance, UEBMI Urban Employees' Basic Medical Insurance, GDP - Gross Domestic Product, OOP - out-of-pocket, THE - total health expenditure, AIC - Akaike information criterion, BIC - Bayesian information criterion, LR test - likelihood ratio test

*, $P<0.1 ; \dagger, P<0.05 ; \ddagger, P<0.01$ 
The random intercept variance at the provincial level indicated that the likelihood of outpatient visits varied across provinces, even after controlling for individual-level factors. Model 2 shows that increases in per capita GDP were positively associated with outpatient care ( $\mathrm{OR}=1.57,95 \% \mathrm{CI}=1.03-2.40)$. In contrast, increases in OOP payment share were negatively associated with outpatient care utilization $(\mathrm{OR}=0.96$, 95\% CI =0.93-0.98). Neither outpatient expenditure per visit nor the number of health professionals per 1000 residents was significantly associated with outpatient service.

Table 3 presents the regression results testing the relationship between provincial health system features and individual-level factors and inpatient care utilization. Compared to the reference groups, male $(\mathrm{OR}=1.11,95 \% \mathrm{CI}=1.01-1.23)$, those aged $60-74(\mathrm{OR}=1.25,95 \% \mathrm{CI}=1.12-1.39)$, those aged 75 years and above (OR=1.43, 95\% CI $=1.20-1.70)$, and those unemployed or retired $(\mathrm{OR}=1.61,95 \% \mathrm{CI}=1.44$ 1.81) were more likely to seek inpatient care, while respondents received high school and above education $(\mathrm{OR}=0.78,95 \% \mathrm{CI}=0.65-0.94)$ and the employed ( $\mathrm{OR}=0.83,95 \% \mathrm{CI}=0.71-0.98)$ were less likely to seek inpatient services. After adjusting for predisposing factors, need factors were the major factors associated with outpatient care utilization. Fair health status $(\mathrm{OR}=1.67,95 \% \mathrm{CI}=1.44-1.93)$, poor health status $(\mathrm{OR}=4.16,95 \% \mathrm{CI}=3.57-4.86)$, and presence of chronic disease $(\mathrm{OR}=2.31,95 \% \mathrm{CI}=2.00-2.65)$ were significantly associated with inpatient care utilization. Furthermore, after adjusting for predisposing and enabling factors, there were statistically significant associations between enabling factors and use of inpatient services. There was a strong gradient in the relationship between economic status and hospitalization. Moreover, compared to the uninsured, respondents covered by health insurance were more likely to utilize inpatient services.

Similar to outpatient care utilization, the likelihood of inpatient service utilization varied across provinces, even after adjusting for individual-level factors. Model 4 shows that OOP payment share was significantly negatively associated with inpatient care utilization ( $\mathrm{OR}=0.98,95 \% \mathrm{CI}=0.97-1.00)$. High health expenditure per admission was also negatively associated with hospitalization $(\mathrm{OR}=0.20,95 \% \mathrm{CI}=0.04$ 0.88). In contrast, the number of ward beds per 1000 residents was significantly positively associated with inpatient care use $(\mathrm{OR}=1.21,95 \% \mathrm{CI}=1.09-1.35)$. Lastly, no significant association was observed between per capita GDP and inpatient care utilization.

\section{DISCUSSION}

To identify the main barriers of access to health care in the ageing population in China, this study analyzed the association of provincial health system characteristics and health care utilization using a multilevel regression model based on nationally representative survey data. We have two main important findings. The first is that large variation exists across provinces in China in terms of the density of health resources, health service expenditure per visit/admission, and the share of OOP payment as THE, reflecting the disparity in health care availability and affordability across China. The second important finding is that affordability of health care is the major barrier to health care utilization among the mid-aged and elderly in China. A high OOP payment share was negatively associated with outpatient and inpatient care utilization, and health expenditure per admission was negatively associated with use of inpatient care. These findings added to the existing evidence on the association between health system characteristics and health care utilization among the mid-aged and elderly in China.

\section{Variation in health system characteristics across provinces in China}

Although the Chinese government has improved the density of ward beds and physicians and decreased user fees for health care services, the disparity in availability and affordability still remains across provinces. During the past ten years, both the number of ward beds and health professionals per 1000 inhabitants increased rapidly [44]. Compared to Organization for Economic Co-operation and Development (OECD) countries, in 2015, China had a higher density of ward beds but a lower density of physicians [45]. Moreover, OOP payments accounted for one-third of THE in China, much higher than that in OECD countries in 2015 [45]. Furthermore, the differences between the highest and lowest values of each health system characteristics across 28 provinces indicates that large variation exists in the density of ward beds and health professionals, health service expenditure per capita, OOP payment share of THE, and health care utilization. Previous cross-sectional studies have revealed disparities in health resource allocations across regions [46-49]. Prior trend analyses also showed that disparity in ward beds narrowed, while prorich inequality among health professionals remained $[44,50]$. 


\section{Bed density associated with inpatient care utilization}

Our results suggest that high availability of ward beds could be positively related with inpatient care utilization among the mid-aged and elderly. This confirms Roemers' hypothesis: an increase in the number of ward beds per capita always increases the hospital utilization rate [51]. Furthermore, a previous study conducted in China suggested that the number of ward beds available is positively associated with the frequency of hospitalization [52]. A plausible reason for the Roemer effect is that high supply of ward beds may induce demands for hospital services. In theory, hospitals face financial incentives to provide additional care to patients when beds are available [53]. An increase in ward bed supply is usually accompanied by an increase in hospital care utilization [54].

\section{Financial affordability associated with health care utilization}

Financial affordability is still a major barrier to universal access to health care in China. The result that the share of OOP payment of THE and per capita health expenditure were negatively associated with health care utilization is consistent with previous studies in other countries [1,55]. It is widely known that universal health care coverage is more likely to be achieved in countries with a lower proportion of OOP payment financing $[2,56]$. Conversely, as the OOP payment share and health care prices increase, the financial burden also increases substantially. This study also confirmed that a higher share of OOP payment was negatively correlated with health care utilization in China. Although the OOP payment share of THE has decreased in recent years, user fees were still an important source of health financing - as high as about $30 \%$. Furthermore, variations in reimbursement rates across different health insurance programs could exacerbate the gaps in OOP spending, which deepens disparities in access to health care. This highlights the importance of adjusting the coinsurance rates of enrollees and consolidating fragmented health insurance schemes to achieve UHC and promote equal access to health care.

More importantly, we found that inpatient expenditure per admission was negatively associated with probability of hospitalization, while outpatient expenditure per visit had no significant relationship with outpatient care utilization. High costs of services are major barriers to health care utilization in both developed and developing countries [16]. However, during the past 20 years, health care costs in China have increased rapidly because of fee-for-service payment and technological innovation $[6,57,58]$. Cost escalation, which obstructs the population's access to health care, is a major concern of the public and the government. It is likely that the price elasticity of demand for outpatient care was low in China, so we did not observe a significant association between outpatient prince and outpatient utilization [59]. The negative correlation between health care price and health care utilization suggests that efforts should be taken to control cost increases and improve patients' affordability for health care services [60,61].

\section{Policy implications}

Our study provides important policy implications for improving equitable access to health care in China. First, China should balance the distribution of health resources. Large variations in the density of warn beds and health professionals exist between high- and low-economic development provinces. The government should develop need-based health resources allocation planning rather than historical increment list method and economic development level in order to balance the distribution of health resources. Second, China should reform health insurance system to decrease high OOP. On one hand, the government should reform providers' payment methods (especially Diagnosis-related groups prospective payment method for acute inpatient services) to control the increase in health care expenditure. On the other hand, the government should increase the reimbursement rates of inpatient services for enrollees of URRBMI and narrow the gaps between UEBMI and URRBMI. Third, China should focus on the unenrolled population. Compared to the enrollees of social health insurance schemes, the uninsured are less likely to use outpatient and inpatient care when they need it. Therefore, strategies, including simplifying enrolment procedure and improving premium collection approaches, should be taken to expand health insurance coverage in the vulnerable groups [62].

UHC is an important global dimension [63]. However, most of low-and middle-income countries (LMIC) have not achieved UHC [64]. Moreover, older adults usually have greater need and require different approaches to health care, but are often less able to pay for services [65]. Population aging is a critical challenge to achiever UHC for LMIC [66]. The findings of this study distinguished main barriers to universal access to health care among the mid-aged and elderly from supply-side. This may have implications on how to realign health financing and resources to meet for UHC targets for LMIC. 


\section{Limitations}

This study has several limitations. First, our analysis used a cross-sectional study design and the results cannot infer causality. Future studies on causal pathways are needed to reveal how health system characteristics influence health care utilization. Second, the measurement of contextual variables was conducted at the provincial level, because data on the county level were not available through the published health statistical yearbook. This may lead to underestimating the associations of health system characteristics and health care utilization. Health system characteristics should be measured at the county level or community level in future studies to capture the within-cluster correlation and contextual effects. Third, the sample size in six provinces was lower than 300 , which may impact the representativeness of samples at provincial level. This may also lead to underestimating the associations of health system characteristics and health care utilization. Forth, the CHARLS data were mainly self-reported, which may create self-report bias in presence of chronic disease and recall bias in household consumption expenditure.

\section{CONCLUSIONS}

The study suggests that large gaps in availability of health resources, health care price and affordability exist across provinces in China. The share of OOP payment as THE and the price of health care play an important role in health care utilization among aging population in China. High OOP and health care price are major financial barriers to accessing health care among the mid-aged and elderly. To improve equal access to health care among the mid-aged elderly, China should allocate health resource according to need-based planning. Most importantly, China should take more priority measures to eliminate the affordability barriers in next phase of health system reforms, such as decreasing the coinsurance rate to reduce the OOP payment share, reforming provider payment methods to control increments in health care prices, and expanding health insurance coverage in vulnerable groups.

Acknowledgements: We would like to acknowledge the China Health and Retirement Longitudinal Study team for providing data. The authors would thank Xinxin Han, PhD, a postdoctoral fellow at the Tsinghua University School of Medicine, for providing valuable feedback on the article. Not applicable as this is a secondary data analysis of a publicly available data set (http://charls.pku.edu.cn/index.html). The CHARLS obtained ethical approval from Ethical Review Committee at Peking University in January 2011.

Funding: This research was supported by Young Scientists Fund of the National Natural Science Foundation of China (Grant No. 71704143), NHC Key Laboratory of Health Economics and Policy Research (Shandong University) (Grant No. NHC-HEPR2019017), and Shandong University (Grant No. IFYT18033).

Authors contributions: CL and HW participated in concept and design. CL and CT participated in acquisition data and data analysis. All authors participated in interpretation, writing the manuscript and approved the final manuscript.

Competing interests: The authors completed the Unified Competing Interest form at www.icmje.org/coi_disclosure.pdf and declare that they have no competing interests.

Additional material

Online Supplementary Document

1 Kim TJ, Vonneilich N, Ludecke D, von dem Knesebeck O. Income, financial barriers to health care and public health expenditure: A multilevel analysis of 28 countries. Soc Sci Med. 2017;176:158-65. Medline:28153752 doi:10.1016/j. socscimed.2017.01.044

2 Carrin G, Mathauer I, Xu K, Evans DB. Universal coverage of health services: tailoring its implementation. Bull World Health Organ. 2008;86:857-63. Medline:19030691 doi:10.2471/BLT.07.049387

3 Evans DB, Hsu J, Boerma T. Universal health coverage and universal access. Bull World Health Organ. 2013;91:546. Medline:23940398 doi:10.2471/BLT.13.125450

4 United Nations. Sustainable Development Goals. 2015. Available: https://www.un.org/sustainabledevelopment/zh/. Accessed: 30 October 2019.

5 Quinguye M, Shenglan T. Universal Health Care Coverage in China: Challenges and Opportunities. Procedia Soc Behav Sci. 2013;77:330-40. doi:10.1016/j.sbspro.2013.03.091 
$6 \mathrm{Yu} \mathrm{H}$. Universal health insurance coverage for 1.3 billion people: What accounts for China's success? Health Policy. 2015;119:1145-52. Medline:26251322 doi:10.1016/j.healthpol.2015.07.008

7 Meng Q, Fang H, Liu X, Yuan B, Xu J. Consolidating the social health insurance schemes in China: towards an equitable and efficient health system. Lancet. 2015;386:1484-92. Medline:26466052 doi:10.1016/S0140-6736(15)00342-6

8 Health and Family Planning Commission of China. Statistical Yearbook of Health and Family Planning of China (2016). Beijing: Peking Union Medical College Press; 2016.

9 Meng Q, Xu L, Zhang Y, Qian J, Cai M, Xin Y, et al. Trends in access to health services and financial protection in China between 2003 and 2011: a cross-sectional study. Lancet. 2012;379:805-14. Medline:22386034 doi:10.1016/S01406736(12)60278-5

10 Yip W, Fu H, Chen AT, Zhai T, Jian W, Xu R, et al. 10 years of health-care reform in China: progress and gaps in Universal Health Coverage. Lancet. 2019;394:1192-204. Medline:31571602 doi:10.1016/S0140-6736(19)32136-1

11 Li C, Dou L, Wang H, Jing S, Yin A. Horizontal Inequity in Health Care Utilization among the Middle-Aged and Elderly in China. Int J Environ Res Public Health. 2017;14:842. Medline:28933772 doi:10.3390/ijerph14080842

12 Zhang X, Wu Q, Shao Y, Fu W, Liu G, Coyte PC. Socioeconomic inequities in health care utilization in China. Asia Pac J Public Health. 2015;27:429-38. Medline:25563350 doi:10.1177/1010539514565446

13 The Lancet. Ageing in China: a ticking bomb. Lancet. 2016;388:2058. Medline:27968735 doi:10.1016/s14744422(07)70162-X

14 Wang X-Q, Chen P-J. Population ageing challenges health care in China. Lancet. 2014;383:870. Medline:24607099 doi:10.1016/S0140-6736(14)60443-8

15 Oliver A, Mossialos E. Equity of access to health care: outlining the foundations for action. J Epidemiol Community Health. 2004;58:655-8. Medline:15252067 doi:10.1136/jech.2003.017731

16 Jacobs B, Ir P, Bigdeli M, Annear PL, Van Damme W. Addressing access barriers to health services: an analytical framework for selecting appropriate interventions in low-income Asian countries. Health Policy Plan. 2012;27:288-300. Medline:21565939 doi:10.1093/heapol/czr038

17 Peters DH, Garg A, Bloom G, Walker DG, Brieger WR, Rahman MH. Poverty and access to health care in developing countries. Ann N Y Acad Sci. 2008;1136:161-71. Medline:17954679 doi:10.1196/annals.1425.011

18 Johar M, Soewondo P, Pujisubekti R, Satrio HK, Adji A. Inequality in access to health care, health insurance and the role of supply factors. Soc Sci Med. 2018;213:134-45. Medline:30077959 doi:10.1016/j.socscimed.2018.07.044

19 Srivastava D, McGuire A. Patient access to health care and medicines across low-income countries. Soc Sci Med. 2015;133:21-7. Medline:25829195 doi:10.1016/j.socscimed.2015.03.021

20 Aday LA, Andersen R. A framework for the study of access to medical care. 1974;9:208-20.

21 Travassos C, Martins M. A review of concepts in health services access and utilization. Cad Saude Publica. 2004;20 Suppl 2:S190-8. Medline:15608933 doi:10.1590/S0102-311X2004000800014

22 Aday LA, Andersen RM. Equity of access to medical care: a conceptual and empirical overview. Med Care. 1981;19:427. doi:10.1097/00005650-198112001-00004

23 Waters HR. Measuring equity in access to health care. Soc Sci Med. 2000;51:599-612. Medline:10868673 doi:10.1016/ S0277-9536(00)00003-4

24 Arueira Chaves L, de Souza Serio Dos Santos DM, Rodrigues Campos M, Luiza VL. Use of health outcome and health service utilization indicators as an outcome of access to medicines in Brazil: perspectives from a literature review. Public Health Rev. 2019;40:5. Medline:31867131 doi:10.1186/s40985-019-0115-1

25 Andersen RM, Rice TH, Kominski GF. Improving access to care in America. In: Andersen RM, Davidson PL, editors. Changing the U S Health Care System: Key Issues in Health Services, Policy, and Management. 2nd ed. California: JosseyBass Inc; 2001. p. 3-30.

26 Evandrou M, Falkingham J, Feng Z, Vlachantoni A. Individual and province inequalities in health among older people in China: evidence and policy implications. Health Place. 2014;30:134-44. Medline:25262491 doi:10.1016/j.healthplace. 2014.08.009

27 Pan J, Shallcross D. Geographic distribution of hospital beds throughout China: a county-level econometric analysis. Int J Equity Health. 2016;15:179. Medline:27821181 doi:10.1186/s12939-016-0467-9

28 Zhang S, Chen Q, Zhang B. Understanding Healthcare Utilization In China Through The Andersen Behavioral Model: Review Of Evidence From The China Health And Nutrition Survey. Risk Manag Healthc Policy. 2019;12:209-24. Medline:31807101 doi:10.2147/RMHP.S218661

29 Fan L, Liu J, Habibov NNJWM, Policy H. A Multilevel Logit Estimation on the Determinants of Utilization of Preventive Health Care and Healthy Lifestyle Practice in China. 2015;7:309-28.

30 Huang C, Liu CJ, Pan XF, Liu X, Li NX. Correlates of unequal access to preventive care in China: a multilevel analysis of national data from the 2011 China Health and Nutrition Survey. BMC Health Serv Res. 2016;16:177. Medline:27177034 doi:10.1186/s12913-016-1426-2

31 Jin Y, Zhu W, Yuan B, Meng Q. Impact of health workforce availability on health care seeking behavior of patients with diabetes mellitus in China. Int J Equity Health. 2017;16:80. Medline:28666449 doi:10.1186/s12939-017-0576-0

32 Zhao Y, Hu Y, Smith JP, Strauss J, Yang G. Cohort profile: the China Health and Retirement Longitudinal Study (CHARLS). Int J Epidemiol. 2014;43:61-8. Medline:23243115 doi:10.1093/ije/dys203

33 Carrasquillo O. Health Care Utilization. In: Gellman MD, Turner JR, editors. Encyclopedia of Behavioral Medicine. New York, NY: Springer New York; 2013. p. 909-10. 
34 Lahiri K, Xing G. An econometric analysis of veterans? health care utilization using two-part models. Empir Econ. 2004;29:431-49. doi:10.1007/s00181-003-0178-0

35 van Doorslaer E, Koolman X, Jones AM. Explaining income-related inequalities in doctor utilisation in Europe. Health Econ. 2004;13:629-47. Medline:15259043 doi:10.1002/hec.919

36 Cylus J, Papanicolas I. An analysis of perceived access to health care in Europe: How universal is universal coverage? Health Policy. 2015;119:1133-44. Medline:26252959 doi:10.1016/j.healthpol.2015.07.004

37 Or Z, Penneau A. A Multilevel Analysis of the determinants of emergency care visits by the elderly in France. Health Policy. 2018;122:908-14. Medline:29807799 doi:10.1016/j.healthpol.2018.05.003

38 Chaupain-Guillot S, Guillot O. Health system characteristics and unmet care needs in Europe: an analysis based on EUSILC data. Eur J Health Econ. 2015;16:781-96. Medline:25186072 doi:10.1007/s10198-014-0629-x

39 Lei X, Sun X, Strauss J, Zhang P, Zhao Y. Depressive symptoms and SES among the mid-aged and elderly in China: Evidence from the China Health and Retirement Longitudinal Study national baseline. Soc Sci Med. 2014;120:224-32. Medline:25261616 doi:10.1016/j.socscimed.2014.09.028

40 Merlo J, Yang M, Chaix B, Lynch J, Rastam L. A brief conceptual tutorial on multilevel analysis in social epidemiology: investigating contextual phenomena in different groups of people. J Epidemiol Community Health. 2005;59:729-36. Medline:16100308 doi:10.1136/jech.2004.023929

41 Sommet N, Morselli D. Keep Calm and Learn Multilevel Logistic Modeling: A Simplified Three-Step Procedure Using Stata, R, Mplus, and SPSS. Rev Int Psychol Soc. 2017;30:203-18. doi:10.5334/irsp.90

$42 \mathrm{Wu}$ S, Crespi CM, Wong WK. Comparison of methods for estimating the intraclass correlation coefficient for binary responses in cancer prevention cluster randomized trials. Contemp Clin Trials. 2012;33:869-80. Medline:22627076 doi:10.1016/j.cct.2012.05.004

43 Heck RH, Thomas SL. Multilevel models with categorical variables. In: Marcoulides GA, editor. An Introduction to Multilevel Modeling Techniques. 53. New York: Routledge; 2015. p. 273-322.

44 Song S, Yuan B, Zhang L, Cheng G, Zhu W, Hou Z, et al. Increased Inequalities in Health Resource and Access to Health Care in Rural China. Int J Environ Res Public Health. 2018;16:49. Medline:30585243 doi:10.3390/ijerph16010049

45 OECD. Health at a Glance 2017: OECD Indicators. 2017. Available: http://dx.doi.org/10.1787/health_glance-2017-en. Accessed: 15 October 2019

46 Liu W, Liu Y, Twum P, Li S. National equity of health resource allocation in China: data from 2009 to 2013. Int J Equity Health. 2016;15:68. Medline:27093960 doi:10.1186/s12939-016-0357-1

47 Wang S, Xu J, Jiang X, Li C, Li H, Song S, et al. Trends in health resource disparities in primary health care institutions in Liaoning Province in Northeast China. Int J Equity Health. 2018;17:178. Medline:30514300 doi:10.1186/s12939018-0896-8

48 Zhang X, Zhao L, Cui Z, Wang Y. Study on Equity and Efficiency of Health Resources and Services Based on Key Indicators in China. PLoS One. 2015;10:e0144809. Medline:26679187 doi:10.1371/journal.pone.0144809

49 Li D, Zhou Z, Si Y, Xu Y, Shen C, Wang Y, et al. Unequal distribution of health human resource in mainland China: what are the determinants from a comprehensive perspective? Int J Equity Health. 2018;17:29. Medline:29486791 doi:10.1186/s12939-018-0742-z

50 Xie X, Liu P, Zheng Y, Zhou W, Zou J, Wang X, et al. Equity of health resource distribution in China during 2009-15: an analysis of cross-sectional nationwide data. Lancet. 2017;390:S6. doi:10.1016/S0140-6736(17)33144-6

51 Taroni F. Roemer's effect reconsidered. J Health Serv Res Policy. 2001;6:56-8. Medline:11219361 doi:10.1258/1355819011927099

52 Jin Y, Zhu W, Zhang Y, Xu L, Meng Q. Impact of health resource allocation on health seeking behavior among inpatients in China. Zhongguo Weisheng Zhengce Yanjiu. 2017;10:51-6.

53 Freedman S. Capacity and Utilization in Health Care: The Effect of Empty Beds on Neonatal Intensive Care Admission. Am Econ J Econ Policy. 2016;8:154-85. Medline:27942353 doi:10.1257/pol.20120393

54 Delamater PL, Messina JP, Grady SC. WinklerPrins V, Shortridge AM. Do more hospital beds lead to higher hospitalization rates? a spatial examination of Roemer's Law. PLoS One. 2013;8:e54900. Medline:23418432 doi:10.1371/journal. pone.0054900

55 Or Z, Jusot F, Yilmaz EJWP. Impact of health care system on socioeconomic inequalities in doctor use. Irdes, 2008.

56 World Health Organization. The world health report 2013: research for universal health coverage. Geneva, Switzerland: WHO Library Cataloguing; 2013.

57 Long Q Xu L, Bekedam H, Tang S. Changes in health expenditures in China in 2000s: has the health system reform improved affordability. Int J Equity Health. 2013;12:40. Medline:23764104 doi:10.1186/1475-9276-12-40

58 Hu S, Tang S, Liu Y, Zhao Y, Escobar M-L, de Ferranti D. Reform of how health care is paid for in China: challenges and opportunities. Lancet. 2008;372:1846-53. Medline:18930520 doi:10.1016/S0140-6736(08)61368-9

59 Zhou Z, Su Y, Gao J, Xu L, Zhang Y. New estimates of elasticity of demand for healthcare in rural China. Health Policy. 2011;103:255-65. Medline:22014842 doi:10.1016/j.healthpol.2011.09.005

60 Yip WC, Hsiao W, Meng Q, Chen W, Sun X. Realignment of incentives for health-care providers in China. Lancet. 2010;375:1120-30. Medline:20346818 doi:10.1016/S0140-6736(10)60063-3

61 Yip WC-M, Hsiao WC, Chen W, Hu S, Ma J, Maynard A. Early appraisal of China's huge and complex health-care reforms. Lancet. 2012;379:833-42. Medline:22386036 doi:10.1016/S0140-6736(11)61880-1

62 Meng Q, Yuan B, Jia L, Wang J, Yu B, Gao J, et al. Expanding health insurance coverage in vulnerable groups: a systematic review of options. Health Policy Plan. 2011;26:93-104. Medline:20813837 doi:10.1093/heapol/czq038 
63 O'Connell T, Rasanathan K, Chopra M. What does universal health coverage mean? Lancet. 2014;383:277-9. Medline:23953765 doi:10.1016/S0140-6736(13)60955-1

64 Wagstaff A, Neelsen S. A comprehensive assessment of universal health coverage in 111 countries: a retrospective observational study. Lancet Glob Health. 2020;8:e39-49. Medline:31837954 doi:10.1016/S2214-109X(19)30463-2

65 Sadana R, Soucat A, Beard J. Universal health coverage must include older people. Bull World Health Organ. 2018;96:2. Medline:29403091 doi:10.2471/BLT.17.204214

66 Goeppel C, Frenz P, Tinnemann P, Grabenhenrich L. Universal health coverage for elderly people with non-communicable diseases in low-income and middle-income countries: a cross-sectional analysis. Lancet. 2014;394:S6. doi:10.1016/ S0140-6736(14)61869-9 